Belma S. Prndelj Šator

UDC [811.112.2:811.163.4]'255

Univerzitet „Džemal Bijedić” u Mostaru

Odsjek za njemački jezik i književnost

Belma.Prndelj@unmo.ba

\title{
PRENOSNE GREŠKE KOD IZVORNIH GOVORNIKA BOSANSKOG/HRVATSKOG/SRPSKOG JEZIKA TOKOM PISANE PRODUKCIJE NA NJEMAČKOM KAO STRANOM JEZIKU
}

\begin{abstract}
Sažetak
U ovladavanju njemačkim kao stranim jezikom neizbježna su odstupanja koja se nerijetko javljaju kao posljedica transfera iz dominantnog jezičkog sistema, a to je maternji jezik kao J1. Ovaj rad se bavi odstupanjima ili greškama koje nastaju kao rezultat preklapanja bosanskog/hrvatskog/ srpskog jezika kao J1 i njemačkog jezika kao J2. Za navedenu analizu poslužili su pismeni radovi studenata Fakulteta humanističkih radova koji uče njemački jezik kao strani jezik, a njihov maternji jezik je bosanski/hrvatski/ srpski jezik - službeni jezici u BiH. Vrši se komparacija prenosnih grešaka u završnim radovima studenata nakon prve i druge godine učenja njemačkog kao stranog jezika. Odstupanja se dijele na: pravopisna, gramatička i leksička. Neke greške nestaju ili se smanjuju na drugoj godini učenja, dok se neka odstupanja prenose iz prve na drugu godinu učenja.
\end{abstract}

Ključne riječi: prenosne greške, bosanski/hrvatski/srpski jezik kao $\mathrm{J} 1$, njemački kao J2, dominantni jezički sistem

\section{UVOD}

Istraživanje je potaknuto iskustvom podučavanja njemačkog kao stranog jezika te pilot istraživanjem provedenim među grupom od 16 polaznika (izvornih govornika bosanskog/hrvatskog/srpskog jezika) kursa njemačkog jezika u Kulturnom centru „Kralj Fahd” u Mostaru. Kod navedenih polaznika je uočeno da najčešće griješe prilikom upotrebe određenog/neodređenog člana, pisanja imenica itd.

$\mathrm{S}$ obzirom na to da je autorica ovog rada po vokaciji germanistica, a maternji jezik joj je bosanski (s tim da se bavila kontrastiranjem njemačkog i sa bo- 
sanskim/hrvatskim/srpskim jezikom), u ovom istraživanju će se analizirati greške koje se pojavljuju kod ispitanika, izvornih govornika bosanskog/hrvatskog/srpskog jezika, koji na Fakultetu humanističkih nauka Univerziteta „Džemal Bijedić" u Mostaru uče njemački kao strani jezik.

Autorica se koristila u radu kontrastivnim pristupom koji se sastoji u identificiranju grešaka koje nastaju kao rezultat interferencije između bosanskog/hrvatskog/srpskog kao maternjeg jezika i njemačkog kao stranog jezika. Ovakvim pristupom se htjela skrenuti pažnja na negativan prenos, kao i na činjenicu da bi se zbog navedenog trebalo u nastavi više insistirati na uvježbavanju određenog područja u njemačkom jeziku, pri čemu bi se izbjegle greške i odstupanja koja nastaju u jezičkoj produkciji koju studenti čine.

Zbog razlika u gramatičkim i leksičkim sistemima dva jezika, maternji jezik može imati negativan utjecaj na napredak u stranom jeziku. Ta se pojava naziva interferencija maternjeg jezika ili negativan jezički transfer. Uočava se analizom grešaka koje se pojavljuju u govoru ili prilikom pisanja kod onih koji uče strani jezik (Petrović 1997: 114).

Nakon učenja dolazi do supostojanja uporednih jezičkih kodova, čime nastaje tzv. međujezičko polje, polje učenja jezika (Pavličević-Fanić 2006: 1). Međujezik koji proizvodi učenik drugog ili stranog jezika je sistem koji ima pravila i odlikuje se odstupanjima kao normalnom pojavom u procesu učenja i ovladavanja drugim jezikom. Odstupanja se definiraju kao otklon od norme jezika koji se uči. Mogu biti prenosna i razvojna. Razvojna se javljaju kao dio procesa učenja i nisu rezultat transfera iz prvog jezika, a prenosna nastaju transferom i utjecajem prvog jezika na drugi (Gulešić-Machata, Udier 2008:20). Pojavljuju se na svim jezičkim razinama: fonetskoj, fonološkoj, morfološkoj, sintaktičkoj, semantičkoj, pragmatičkoj i kulturološkoj (Jelaska 2005: 101). Zastupljenost prenosnih odstupanja zavisi o stepenu znanja onog koji uči. Na početnom nivou ih ima mnogo, dok se kasnije ta odstupanja smanjuju, a razvojna odstupanja su u porastu (Macan i Kolaković 2008: 35).

\subsection{GRAĐA I ISPITANICI}

U ovom radu su kao izvor za analizu korišteni testovi, diktati i završni pismeni radovi studenata Odsjeka za engleski jezik i književnost, Odsjeka za bosanski/hrvatski/srpski jezik i književnost, Odsjeka za historiju/istoriju/povijest i Odsjeka za komunikologiju Fakulteta humanističkih nauka Univerziteta „Džemal Bijedić" u Mostaru koji u sastavu svog plana i programa studiranja imaju njemački jezik kao izborni predmet. Prikupljeni su u akademskoj 2012/2013. godini. Ispitanicima je glavni jezik, tj. J1, bio bosanski/hrvatski/srpski. Na njihovim rado- 
vima su se analizirala najučestalija prenosna odstupanja iz b/h/s kao J1 u njemački kao J2. Građa je podijeljena na dva dijela. U prvom dijelu su analizirani radovi studenata koji polažu Njemački jezik I i II (prva godina učenja, 120 sati ukupno) i onih koji polažu Njemački jezik III (druga godina učenja, 60 sati ukupno). Bilo je 70 radova sa prve i 70 radova sa druge godine.

\subsection{Pretpostavke}

$\mathrm{Na}$ osnovu prijašnjih istraživanja koja su se bavila problematikom ovog rada prilikom učenja drugih jezika može se pretpostaviti da će tip kao i zastupljenost određenog odstupanja tokom učenja njemačkog jezika zavisiti od stepena znanja studenata. Očekivala su se odstupanja na svim jezičkim razinama, i kod studenata koji su učili Njemački jezik I i II, i kod onih koji su pohađali nastavu iz Njemačkog jezika III. Međutim, pretpostavljalo se da će se navedena odstupanja razlikovati po karakteristikama i zastupljenosti. Želi se, također, pokazati i ukazati na najčešća prenosna odstupanja kod studenata $\mathrm{b} / \mathrm{h} / \mathrm{s} \mathrm{J} 1$ te kako se ona mijenjaju ili ne mijenjaju sa povećanjem znanja njemačkog jezika.

Poređenje međujezika i dominantnog jezičkog sistema vrlo je važno za razumijevanje i otklanjanje odstupanja pri učenju njemačkog J2.

Rezultati ovog rada moći će doprinijeti boljoj i kvalitetnijoj nastavi njemačkog kao stranog jezika. Nastavnik će biti upućen koja odstupanja može očekivati te će na taj način moći uložiti više vremena i truda kako bi na vrijeme spriječio ukorijenjivanje određenih odstupanja.

\subsection{VRSTE PRENOSNIH ODSTUPANJA IZ B/H/S KAO J1 U NJEMAČKI KAO J2}

Ponekad je teško odrediti o kojoj vrsti odstupanja se radi jer se pojedini primjeri mogu tumačiti na više načina, ili pak uključuju više od jedne razine. U ovom radu je napravljena podjela na tri osnovne vrste: pravopisna odstupanja (uključujući i fonološka), gramatička (obuhvataju morfološka i sintaktička) i leksička, u kojima su razdvojena tvorbena i semantička.

\section{PRAVOPISNA ODSTUPANJA}

Pravopisna odstupanja se odnose samo na pisani jezik. Međutim, rezultati ukazuju na to da pravopisna odstupanja mogu biti povezana sa izgovornim, primjerice pri obezvučenju šumnika, što je jedan od razloga uključivanja i fonoloških odstupanja u ovu skupinu. 
2.1. Pravopisna odstupanja Kod StUdenata PRVE GODINE UČENJA

U radovima studenata koji su učili njemački jezik jednu akademsku godinu česta su pravopisna (ortografska) odstupanja, tj. prenošenje pravopisnih obilježja iz b/h/s J1 u njemački J2.

Pisanje imenica malim početnim slovom - U njemačkom jeziku se imenice pišu velikim početnim slovom, što nije slučaj u J1 pa nastaju vrlo često odstupanja kao u (1).

(1) i. er ist 38 jahre alt

(umj. Jahre)

ii. und liest eine zeitung

(umj. Zeitung)

iii. finden Sie lampen

(umj. Lampen)

Zamjena grafema - kao u (2).

(2) i. und spricht Francözisch

(umj. Französisch)

(z se u njemačkom jeziku izgovara kao $\mathbf{c}$, a s na početku riječi i sloga kao z, što nije slučaj u J1)

ii. Geschlecht: veiblich

(umj. weiblich)

(w se u njemačkom jeziku izgovara kao v, što nije slučaj u J1. Abeceda J1 ne sadrži grafem w)

iii. aber auch fiele günstige Angebote

(umj. viele)

(v se u njemačkom jeziku u većini slučajeva izgovara kao f, osim kod nekih riječi stranog porijekla Violine, Vokativ itd).

iv. und begrist die Nachbarin

(umj. begrü̈ $\beta$ )

(J2 poznaje preglašene samoglasnike ä, $\ddot{\mathbf{o}}$, i $\ddot{\mathbf{u}}$, te slovo $\boldsymbol{B}$, što nije slučaj u J1. Govornici J1 navedene grafeme realiziraju u pisanoj produkciji grafemima e, i i s.)

Izostavljanje grafema - kao u (3).

(3) i. und begrüßt di Nachbarin

(umj. die)

(Diftong ie se u J2 izgovara kao dugo i. Izvorni govornici J1 ne poznaju navedeni diftong, te ga produciraju u pismenoj formi onako kako se izgovara, kao i.)

ii. abe keine Küche

(umj. aber)

(r se na kraju sloga u J2 obično ne izgovara, što nije slučaj u J1. Ono se često ,vokalizira” u J2, posebno iza dugog vokala/samoglasnika i kod nenaglašenih nastavaka. Takvo $\mathbf{r}$ se realizira kao [e].)

iii. im Kaufhaus gibt es fast ales

(umj. alles)

(Kratki izgovor samoglasnika pojavljuje se kod udvojenog suglasnika koji slijedi iza samoglasnika u J2, dok se u bosanskom/hrvatskom/srpskom jeziku udvojeni suglasnici samo pišu u superlativu pridjeva na $j$, npr. najjači, i u nekim složenicama radi lakšeg razumijevanja, npr. vannastavni.) 
Obezvučavanje ili obezvučenje kao u (4). Ova glasovna promjena (u b/h/s jeziku se koristi termin „obezvučavanje ili obezvučenje suglasnika na kraju sloga/ riječi”, a u njemačkom jeziku „Auslautverhärtung”) je česta kod studenata prve godine učenja, dok izvorni govornici njemačkog jezika koji uče hrvatski jezik (u prvoj godini učenja) zamjenjuju bezvučne šumnika zvučnim (npr. Orlandov stub, umj. stup; imam ped kornjača, umj. pet) (Macan i Kolaković 2008: 38).

(4) i. er hat keinen Hert

(umj. Herd)

ii. er hat keinen Staupsauger

(umj. Staubsauger)

\subsection{Pravopisna odstupanja kod studenata druge godine učenja}

I studenti koji njemački jezik uče drugu godinu prenose pravopisne karakteristike iz $\mathrm{J} 1 \mathrm{u} \mathrm{J} 2$, mada su kod studenata druge godine ove greške mnogo rjeđe.

Pisanje imenica malim početnim slovom - U njemačkom jeziku se imenice pišu velikim početnim slovom, što nije slučaj u J1. Ovakvih odstupanja je vrlo malo kod studenata druge godine učenja, ali se još uvijek pojavljuju kao u (5).

(5) i. Deutschland ist ein großes land

(umj. Land)

ii. hast du hunger?

(umj. Hunger)

(Pretpostavlja se da su studenti pisali riječ Hunger „glad” malim početnim slovom, razmišljajući na J1. U J1 se ne postavlja pitanje, kao u J2, „imaš li glad?” nego ,jesi li gladan", dakle koristi se pridjev koji se u oba jezika piše malim početnim slovom.)

Izostavljanje grafema - kao u (6). Ovakva odstupanja su vrlo rijetka kod studenata druge godine učenja. Uglavnom je to slučaj kod udvojenog suglasnika koji slijedi iza samoglasnika.

(6) i. vor einem Jahr konte er noch kein Wort Deutsch

(umj. konnte)

ii. warum hatest du keine Zeit

(umj. hattest)

Obezvučavanje ili obezvučenje - kao u (7). Ovakvih odstupanja je kod studenata druge godine učenja manje.

(7) i. wir sint im Kino

(umj. sind)

ii. obwohl du wenig Gelt hast (umj. Geld)

Upotreba zareza - Odstupanje koje se tek pojavljuje na ovom stepenu proizlazi iz većeg obima poznavanja jezika. Studenti druge godine učenja već koriste složene rečenice koje prije nisu poznavali. Tako se pojavljuje prenos pravila iz J1 o nepisanju zareza ispred svake zavisne rečenice kao u (8), iako se u njemačkom jeziku u takvim primjerima stavlja zarez. Obrnuto odstupanje se pojavljuje kod izvornih govornika njemačkog jezika koji uče hrvatski jezik (npr. Ona zna, da me uvijek može nazvati; Definicija prijateljstva je teška, jer je to apstraktan pojam. itd.) (Macan i Kolaković 2008: 39). 
(8) i. Andrea hat wenig Zeit weil sie arbeiten muss. (umj. Andrea hat wenig Zeit, weil sie arbeiten muss)

ii. Wir waren im Kino obwohl wir zu Hause bleiben wollten. (umj. Wir waren im Kino, obwohl wir zu Hause bleiben wollten.)

\section{GRAMATIČKA ODSTUPANJA}

Gramatička odstupanja su rezultat prenošenja gramatičkih obilježja iz J1 u J2. Tu se misli na: red riječi u rečenici (prostoj i složenoj), upotrebu određenog i neodređenog člana, upotrebu roda, konjugaciju, padež, upotrebu prijedloga, ispuštanje ličnih zamjenica, negaciju sa nicht i kein/keine/kein itd.

\subsection{GRAMATIČKA ODSTUPANJA KOD STUDENATA PRVE GODINE UČENJA}

Lični glagolski oblik u izjavnoj rečenici - U njemačkom jeziku vrijedi pravilo da se lični glagolski oblik u izjavnoj rečenici uvijek pojavljuje na drugom mjestu, što nije slučaj u J1. Odstupanja od navedenog pravila pronalazimo u (9).

(9) i. Martina heute geht ins Möbelhaus.

(umj. Martina geht heute ins Möbelhaus.)

ii. Heute sie kauft eine Stereoanlage. (umj. Heute kauft sie eine Stereoanlage.)

Upotreba određenog ili neodređenog člana - U J2 postoji kategorija određenog i neodređenog člana (koji se slažu sa imenicom u rodu broju i padežu). U skladu s tim, postoje i striktna pravila kada se i koji član koristi, odnosno kada se član ne upotrebljava. S obzirom na to da je b/h/s jezik bez članova, za izražavanje određenosti i neodređenosti se uglavnom koriste: a) kratki i dugi oblici pridjeva; b) broj jedan i c) pokazne i nedređene zamjenice, tako da se kod studenata koji uče njemački jezik dešavaju odstupanja kao u (10).

(10) i. Wien ist Hauptstadt von Österreich. (umj. Wien ist die Hauptstadt von Österreich.)

ii. Ich suche den Kräutertee. (umj. Ich suche Kräutertee.)

Rod imenica - Rod imenica u J1 ne odgovara uvijek rodu imenica u J2. Nastaju odstupanja kao u (11).

(11) i. Wien ist der Hauptstadt von Österreich und er hat... (umj. Wien ist die Hauptstadt von Österreich und sie hat...)

(Imenica „grad” je u njemačkom jeziku ženskog roda, dok je u bosanskom/ hrvatskom/srpskom jeziku muškog roda.)

ii. Es gibt eine Sessel. (umj. Es gibt einen Sessel.) 
(Imenica „fotelja” je u J2 muškog roda.)

iii. ein Packung Waschpulver

(umj. eine Packung Waschpulver)

(Imenica „pakovanje” u J1 je srednjeg roda, dok su u J2 sve imenice koje završavaju sufiksom -ung ženskog roda.)

Prezent u 2. i 3. licu jednine - U njemačkom jeziku kod određenog broja glagola koji unutar glagolske osnove imaju samoglasnik $e$, u 2. i 3. licu jednine dolazi do glasovne promjene e u i ili ie (u njemačkom jeziku e/i-Wechsel) (Tanović 2004: 139). To nije slučaj u J1, te dolazi do odstupanja kod glagola koji imaju navedenu glasovnu promjenu u prezentu jednine kao u (12).

(12) i. Du sprechst auch Englisch.

(umj. Du sprichst auch Englisch.)

ii. Er helft Sarah bei den Hausaufgaben. den Hausaufgaben.)

iii. Und was nehmst du?

(umj. Und was nimmst du?)

Upotreba prijedloga - Prijedlozi su u J1 i u J2 nepromjenljive riječi koje zahtijevaju određene padeže. Međutim, isti prijedlozi u J1 i u J2 se ne slažu uvijek sa istim padežom ( $k o d$ se slaže u J1 sa genitivom, dok se u J2 slaže sa dativom) kao u (13).

(13) i. bei der Würstwaren

(umj. bei den Würstwaren)

ii. von ihrer Kinder

(umj. von ihren Kindern)

Negacija - U njemačkom jeziku se za negiranje može koristi kein i nicht (Ich trinke keinen Saft; Ich trinke heute nicht). Postoje pravila kada se koristi jedna negacija, a kada druga, dok to nije slučaj u b/h/s jeziku. U J1 se upotrebljava negacija ne (Ne pijem sok; Danas ne pijem). Nastaju odstupanja kao u (14).

(14) i. Sie trinkt nicht Orangensaft. (umj. Sie trinkt keinen Orangensaft.)

ii. Martina ist keine verheiratet.

iii. Sie hat nicht Kinder.

(umj. Martina ist nicht verheiratet)

(umj. Sie hat keine Kinder.)

\subsection{GRAMATIČKA ODSTUPANJA KOD STUDENATA DRUGE GODINE UČENJA}

Red riječi u zavisnoj rečenici - U J2 lični glagolski oblik u zavisnoj rečenici uvijek dolazi na posljednje mjesto, dok to nije slučaj u J1. Nastaju odstupanja kod studenata druge godine učenja koji već koriste složene rečenice, kao što je to slučaj u (15).

(15) i. Wir sind im Kino, obwohl wir sollen zu Hause bleiben. (umj. Wir sind im Kino, obwohl wir zu Hause bleiben sollen.)

ii. Du lernst schnell Deutsch, weil du lebst und arbeitest in Deutschland. (umj. Du lernst schnell Deutsch, weil du in Deutschland lebst und arbeitest.)

Perfekt - U J1 perfekt se tvori od enklitičkih prezentskih oblika glagola jesam, dok se u njemačkom kao pomoćni glagol koriste glagoli biti (sein) i imati 
(haben). Kod studenata druge godine učenje prisutna su odstupanja koja su rjeđa od onih u (15), kod upotrebe pomoćnog glagla haben kao u (16).

(16) i. Ich bin am Strand in der Sonne gelegen. (umj. Ich habe am Strand in der Sonne gelegen.)

ii. Sie ist viele Sehenswürdigkeiten besichtigt. (umj. Sie hat viele Sehenswürdigkeiten besichtigt.)

Ispuštanje ličnih zamjenica - U J2 se samo u rijetkim slučajevima ispušta izricanje subjekta jer u tom slučaju rečenica nije gramatički ispravna. Međutim, u J1 upotreba ličnih zamjenica nije nužna. Nastaju odstupanja kao u (17).

(17) i. Tom möchte ein neues Auto kaufen, obwohl wenig Geld hat. (umj. Tom möchte ein neues Auto kaufen, obwohl er wenig Geld hat.)

ii. Anja macht viele Fehler, obwohl schon ein Jahr Deutsch lernt. (umj. Anja macht viele Fehler, obwohl sie schon ein Jahr Deutsch lernt.)

Rod imenica - Iako se rod imenica u J1 i J2 često ne slažu, kod studenata druge godine učenja njemačkog jezika, rjeđa su ovakva odstupanja kao u (18), nego kod studenata početnika.

(18) i. Deutschland ist eine große Land.

(umj. Deutschland ist ein großes Land.)

Zamjena veznika - Veznik kada u J1 se na njemački jezik može prevesti njemačkim wenn (za radnju koja se odvija u sadašnjosti ili se ponavljala više puta u prošlosti) i als (za radnju koja se dogodila jednom u prošlosti). U (19) studenti su pogrešno upotrebljavali veznike wenn i wann koji odgovaraju $\mathrm{b} / \mathrm{h} / \mathrm{s}$ vezniku kada.

(19) i. Wenn ich aufgestanden bin, habe ich zuerst gegessen. (umj. als) ii. Als ich koche, singe ich oft.

(umj. wenn)

\section{TVORBENA PRENOSNA ODSTUPANJA}

Treću skupinu odstupanja koja su se pojavila u analiziranim testovima čine leksička odstupanja. Ona su podijeljena na leksičko-tvorbena i leksičko-semantička odstupanja, iako je ponekad teško povući granicu.

\subsection{TVORBENA ODSTUPANJA STUDENATA PRVE GODINE UČENJA}

Za razliku od bosanskog, hrvatskog i srpskog jezika njemački jezik je sklon slaganju kao vrsti tvorbe. Nesklonost J1 za tvorbom složenica se očituje u (20), gdje je naveden primjer leksičko-tvorbenog odstupanja studenata prve godine učenja. 
(20) i. Salami ist kein Milch Produkt

ii. Salama nije mliječni proizvod.

iii. Elektronik Abteilung

iv. odjel za elektroniku

(umj. Milchprodukt)

(umj. Elektronikabteilung)

\subsection{TVORbenA ODSTUPANJA STUDENATA DRUGE GODINE UČENJA}

Studenti druge godine učenja, također, nisu skloni tvorbi složenica kao u (21).

(21) i. Staat in Mittel Europa

ii. Srednja Evropa

iii. Kulture Zentrum

iv. centar kulture

(umj. Mitteleuropa)

(umj. Kulturzentrum)

\section{LEKSIČKO-SEMANTIČKA ODSTUPANJA}

U prikupljenom korpusu zastupljen je veliki broj pojedinačnih primjera prenosnih leksičko-semantičkih odstupanja. Česta je pojava zamjena leksičkog elementa J2 elementom J1. Prenos leksičkih elemenata različitog značenja u J1 i J2 može se očitovati kao upotreba doslovno prevedenih riječi koje se u njemačkom jeziku ne koriste. Uzrok je višeznačnost riječi u J1 kojim u J2 odgovaraju različite riječi, ali i homonimija.

\subsection{LEKSIČKO-SEMANTIČKA ODSTUPANJA STUDENATA PRVE GODINE UČENJA}

Odabir neprikladnog značenja polisemične riječi - Ukoliko se prenosi neprikladno značenje, najčešće se radi o polisemičnim riječima. U (22) b/h/s glagolu voljeti odgovara njemački glagol mögen, a ne lieben.

(22) i. Ich liebe Rockmusik.

(umj. mag)

ii.Volim rok muziku.

Neprikladno značenje je odabrano i kod pridjeva visok koji se trebao u (23) prevesti njemačkim pridjevom groß, te kod glagola ići koji se trebao prevesti njemačkim glagolom fahren.

(23) i. Er ist hübsch und hoch.

(umj. gro $\beta$ )

ii. On je lijep i visok.

iii. Wir gehen im Sommer in die Türkei.

iv. Idemo na ljeto u Tursku.

(umj.fahren) 
Odabir nepostojećeg značenja - Za iskazivanje starosne dobi u bosanskom/ hrvatskom/srpskom jeziku se koristi glagol imati. Međutim, ukoliko se doslovno prevede na njemački jezik, dobijamo nepostojeće značenje kao u (24).

(24) i. Ich habe 24 Jahre.

ii. Imam 24 godine.

(umj. bin)

Zanimljivo je da studentice prve godine učenja, kada navode svoj spol, koriste imenice Frau (,žena, gospođa”) i Dame („dama”) kao u (25), a ne odgovarajući pridjev weiblich (,ženski”), izveden od zastarjele imenice Weib (,žensko, žena").

(25) i. Geschlecht: Frau/Dame

(umj. weiblich)

\subsection{Leksičko-semantička odstupanja studenata druge godine učenja}

U radovima studenata druge godine učenja često se pojavljuje odabir riječ $i$ neprikladnog značenja kao u (26) i (27). Kod (26) lekseme Kaffee i Cafe ekvivalentne su na ortoepskom nivou. Radi se o homonimima (Kafee znači „kafa”, a Cafe „kafić”).

(26) i. Ich bin im Kaffee mit meinen Freunden. , (umj. Cafe)

ii. Ja sam u kafiću sa svojim prijateljima.

(27) i.Im Norden von Deutschland hat Meer. ii. Na sjeveru Njemačke ima more.

(umj. gibt es)

\section{ZAKLJUČAK}

Rezultati do kojih se došlo u ovom radu ukazuju da se u procesu učenja njemačkog kao stranog jezika pojavljuje veći broj prenosnih grešaka koje su nastale kao posljedica prenošenja jezičkih elemenata iz dominantnog sistema J1 u J2.

Potvrdila se pretpostavka da će na drugoj godini učenja neke greške nestati, ali da će se pojaviti neke nove. Među studentima prve godine česta su pravopisna odstupanja koja iščezavaju na drugoj godini (pisanje imenica malim početnim slovom). Međutim, zamjena bezvučnih i zvučnih šumnika je odstupanje koje se pojavljuje i na drugoj godini te se shodno tome treba uložiti više napora kako bi se to korigiralo.

U radovima studenata druge godine bilo je manje pravopisnih grešaka, ali se pojavilo više gramatičkih i leksičkih grešaka. To se može povezati sa povećanjem nastavnog gradiva i vokabulara. Na obe godine se može primijetiti kako studenti imaju poteškoće sa tvorbom složenica, čemu je sklon njemački jezik. 
Rad nastavnika i lektora trebalo bi da se usredotoči na odstupanja koja se pojavljuju kod studenata, posebno se treba posvetiti onim greškama koje se prenose sa nižih na više razine učenja.

\section{LITERATURA}

Buscha, J., \& Helbig, G. (1996). Deutsche Grammatik. Leipzig: Langenscheidt. Dudenredaktion. (1996). Deutsches Universalwörterbuch. Mannheim - Leipzig Wien - Zürich: Dudenverlag.

Gulešić-Machata, M., \& Udier, S. (2008). Izvorna odstupanja u hrvatskome kao inojezičnome. Lahor, 1(5), 19-33.

Jelaska, Z., et al. (2005). Hrvatski kao drugi i strani jezik. Zagreb: Hrvatska sveučilišna naklada.

Macan, Ž., \& Kolaković Z. (2008). Prijenosna odstupanja govornika njemačkoga u ovladavanju hrvatskim jezikom. Lahor, 5, 34-52.

Pavličević-Franić, D. (2006). Jezičnost i međujezičnost između sustava, podsustava i komunikacije. Lahor, 1, 1-14.

Petrović, E. (1997). Teorija nastave stranih jezika. Osijek: Pedagoški fakultet.

Tanović, M. (2004). Morfologija njemačkog jezika. Mostar: Fakultet humanističkih nauka.

\section{Belma S. Prndelj-Šator}

THE WRITTEN PRODUCTION OF STUDENTS LEARNING GERMAN AS A FL: EXAMPLES OF A NEGATIVE TRANSFER FROM BOSNIAN/CROATIAN/SERBIAN

\section{Summary}

While learning German as a second or foreign language errors are bound to occur. Some of them are result of the transfer from a dominant language system (usually the mother tongue L1). This paper analyses final papers in written language of students who are learning German as a foreign language at the University „Džemal Bijedić“ in Mostar (Faculty of Humanities) and whose mother tongue is either Bosnian, or Croatian, or Serbian. Therefore, errors that occur as a result of an overlap between Bosnian/Croatian/ Serbian as a first and German as a second language will be compared.

The data consisted of 70 final papers from first year students who had approximately 120 hours of German, and 70 final papers from students who had altogether approximately 180 hours of German (approximately 60 hours in the second year). 
Depending on which elements are transferred, a phonological and orthographic level, a grammatical level, a lexical-semantic level of transfer could be differentiated. As the data only consisted of written language, no phonetic errors could be recorded. Developmental errors were not analysed, but as it is not always easy to distinguish them from other types of errors, and since some examples included them, they were just briefly mentioned.

The hypothesis tested was that some transfer errors will disappear at higher levels of German knowledge, some of them will appear less frequently, while new ones will appear with more complex language knowledge. The analysis was qualitative, not quantitative: the investigation included types of errors that were classified with examples, and not the exact numbers of errors that were found.

The hypothesis was confirmed. While the beginners' level of knowledge was characterized by various orthographic errors, second year students stopped transferring most of them. Both levels had equal variety of error types on the grammatical level. The higher level had more lexical errors then the lower level, due to a larger vocabulary and more complex semantic demands.

Although comparative analysis showed that some errors caused by linguistic transfer that occurred while learning German as an L2 were persistant, those were, like in the case of a substitution of letters representing voiced sounds for voiceless $(d / t, p / b)$, due to the Bosnian/Croatian/Serbian orthographic system.

Key words: transfer errors, Bosnian/Croatian/Serbian as L1, German as L2, errors caused by linguistic transfer, level of transfer, dominant language system. 